the education of all children, and if from so impoverished a soil Dr. Guggenbühl has drawn such fruits, what might not be expected if the bodies and minds of children amply blest with vigour and intelligence were developed with an equal care?

Our space compels us to take leave of this important work, but we trust that even these few observations may excite the interest of some among our readers who may possess the power of aiding Dr. Guggenbühl in his self-imposed task. He has already found potent aid from English pens, and the cause which has received the earnest support of Forbes and Conolly can scarcely want an advocate now. Still we cannot refrain from adding our tribute of sympathy and admiration for a man who has so nobly endeavoured to remove one of the greatest afflictions of humanity, and to restore to the poor cretin his birthright of intelligence.

\title{
Review X.
}

Urinary Deposits-their Diagnosis, Pathology, and Therapeutical Indications. By GoLding BIRD, A.M., M.D., F.R.S., Fellow of the Royal College of Physicians; Assistant Physician to, and Lecturer on Materia Medica and Therapeutics at, Guy's Hospital. Fourth Edition, Revised and Enlarged.-London, 1853.

No subject in the range of medical science has made greater progress within the last few years than that relating to the chemistry and pathology of the urine; this is partly owing to the rapid advances which have of late been made in organic chemistry, through the labours of Liebig, Mülder, Lehmann, Simon, Robin, and many others; and partly to the vast importance of the subject in a pathological point of view. One consideration alone will serve to bring home to the mind the value of a correct knowledge of the composition of the urine in health and disease.

The office of the kidney is to separate from the blood the various excrementitious substances contained in that fluid, a variety of salts, and many other bodies and compounds, the products of deranged or morbid action; and hence, the composition of the urine fully made out, affords an accurate and important indication of the many changes which are constantly going on, either in the system at large, or in particular organs.

While we are very desirous that the following review should be characterized by the strictest impartiality, we yet reserve to ourselves the right of freely and frankly commenting upon any portions of the work before us which appear to call for observation.

Although but little more than eight years have elapsed since the treatise by Dr. Golding Bird on urinary deposits was first published, it has already gone through no less than four editions; a fact, which, in itself, affords very strong evidence both of its merits and of the interest felt in the subject of which it treats.

The great characteristic of this work is, that it is eminently practical; it gives a clear and simple account, under separate heads, of each of the more important normal and abnormal constituents found in the urine, 
with instructions for treatment. To the student or practitioner, therefore, desirous of acquiring merely a general knowledge of the chemistry and pathology of the urine, and of the treatment of the more ordinary deviations from health, the work in question is an admirable guide.

This treatise, however, must not be regarded as of a complete and comprehensive character, for it does not attempt to embrace all the facts and observations connected with the urine which the united labours of many observers have made known to us. We notice many deficiencies in this respect; and the truth of the remark is acknowledged by Dr. Bird himself, in the following observation, which forms part of the preface to the present edition:

"If in any case I may appear not to have noticed some of the more recent contributions to the literature of the profession on the now popular subject of urinary pathology, it has not been from oversight or want of respect to their authors, but simply from their having been unsupported by my own observations."

The reason assigned by Dr. Bird for these omissions is evidently of a very unsatisfactory character. If an author is to be permitted to exclude all matter which does not happen to be supported by his own observations, he would, in a case like the present, have to reject a very large proportion of what is published on the subject; for in an extended and complex subject like that of the chemistry and pathology of the urine, no one observer can possibly verify for himself all the facts and observations brought to light by the efforts of many inquirers. The course adopted by Dr. Bird is neither fair to his readers nor just towards his contemporaries. The correct course to take is to notice all new contributions in their proper places: if erroneous, to refute them; and if not within the range of the author's own special observations, to admit them on the responsibility of their respective writers.

Nor has Dr. Bird himself strictly followed out the line of conduct which he has laid down, inasmuch as he treats of many things connected with the urine which could not possibly have fallen under his own immediate observation; but still he has acted upon it to such an extent as to expose himself to the charge of partiality, and also to deprive his work of that completeness and comprehensiveness which it ought to possess.

The present edition of the work is divided into fourteen chapters. Chapter I. consists of "Preliminary Details connected with the Chemistry of the Urine," and contains directions for the detection of its chief constituents. This is a very useful and important chapter, and would have been much more so, had the directions been of a fuller and more complete description. To have done justice to this subject, the chapter ought to have been as long again.

The details with respect to the mode of detecting and obtaining creatine and creatinine especially are very imperfect, a short process only being given for the formation of a compound of zinc and chlorine, with creatine and creatinine. No directions are furnished in this place for procuring these important constituents of the urine in a separate form. But it is mainly by the absence of full microscopical instructions that the chapter is rendered so defective. Nothing is said with respect to the microscopical characters of urea, creatine, or creatinine, in the urine; although these are 
in many cases so well defined that their detection by means of the microscope becomes extremely easy.

It was long since pointed out by the reviewer,* that urea almost constantly crystallizes when urine is evaporated, presenting several well-marked modifications in the character and form of its crystallization. If containing urea in large quantities, a few drops only of urine, allowed to evaporate spontaneously, leave a considerable satin-like crystalline crust upon the glass, which, viewed under the microscope, presents a beautiful radiated arrangement, resulting from the union of numerous more or less elongated and linear crystals. See fig. 1 .

U R E A.

Fig. 1.

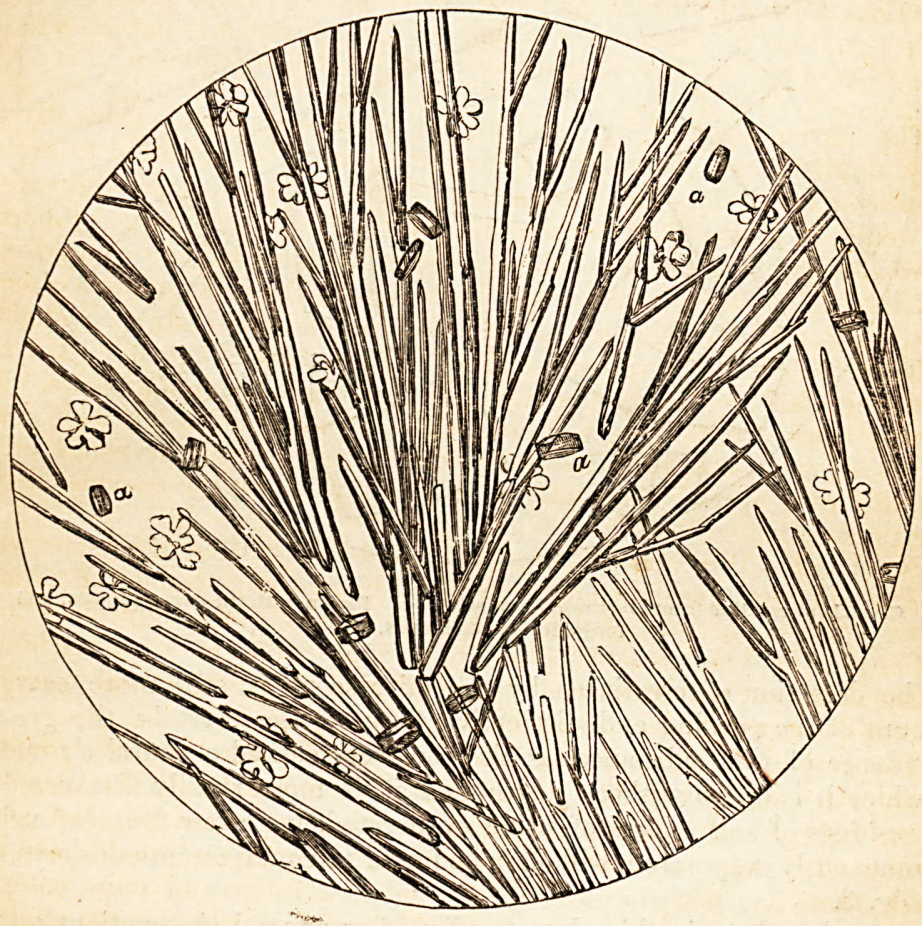

Urea from two or three drops of human urine, allowed to evaporate spontaneously on a slip of glass, $a, a$. Crystals of creatinine. Drawn with the camera lucida, and magnified 90 diameters.

Creatine may likewise be detected in the urine by the microscope alone. Crystals of creatine from human urine are represented in the Atlas of MM. Robin and Verdeil, in plate XXV., figs. 1 and 2 ; and we have also detected certain modifications of them, particularly in the syrup-like residues of half-ounces of urine carefully evaporated over a water-bath. 
C R E A T I N E.

Fig. 2

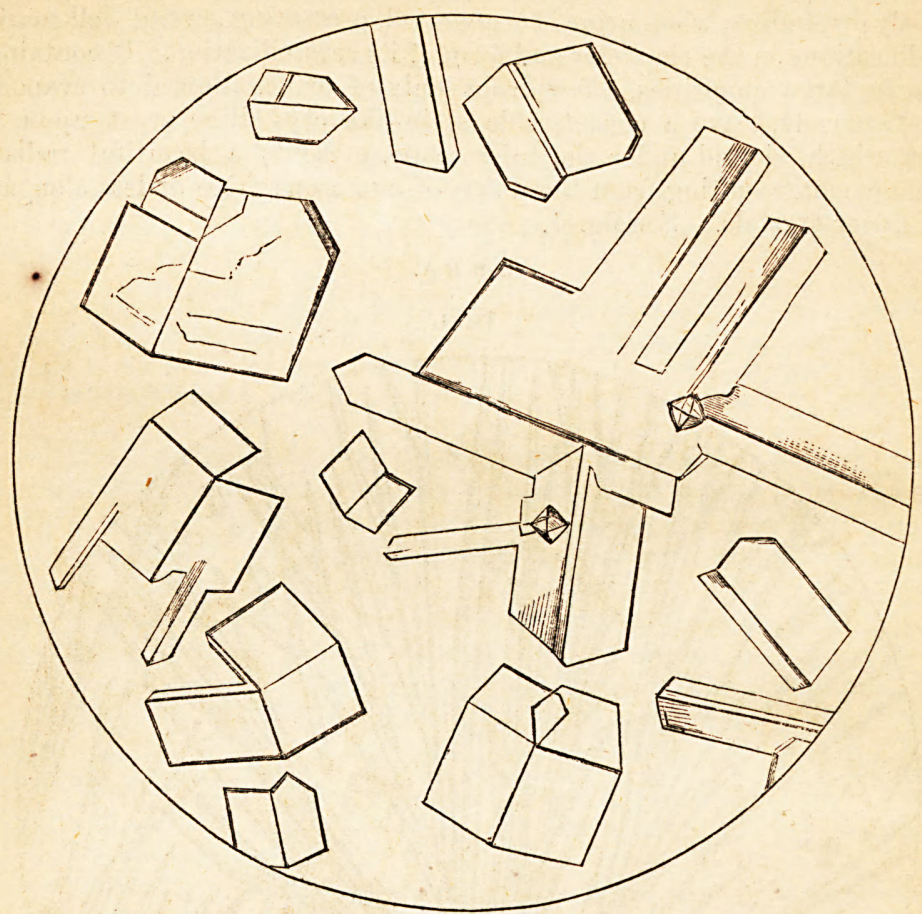

Crystals of creatine from inspissated human urine. Drawn with the camera lucida, and magnified 100 diameters.

The detection of creatinine by the microscope is still more easy, on account of the peculiar and distinctive form of the crystals, the greater abundance of this substance, as also the well-marked chemical characters by which it is distinguished. Although it is most readily discovered in the residues of half ounces of urine evaporated, yet a few drops of urine, spontaneously evaporated, will often be found to contain numerous crystals. See fig. 3.

It may be of use, in this place, to offer a few general observations on the application of the microscope to the study of the urine.

A knowledge of the composition of the urine nay be arrived at by two means, which may be employed either separately or in combination, as may be required: the one chemical, the other microscopical. The latter, in many cases, possesses great advantages over the former, particularly in the rapidity and simplicity with which results may be obtained by it. So long as it is necessary to institute complicated and tedious chemical analyses, in order to acquire a knowledge of the composition of the urine, the study of that fluid cannot be generally pursued by those who are 


\section{CREATININE.}

Fig. 3.

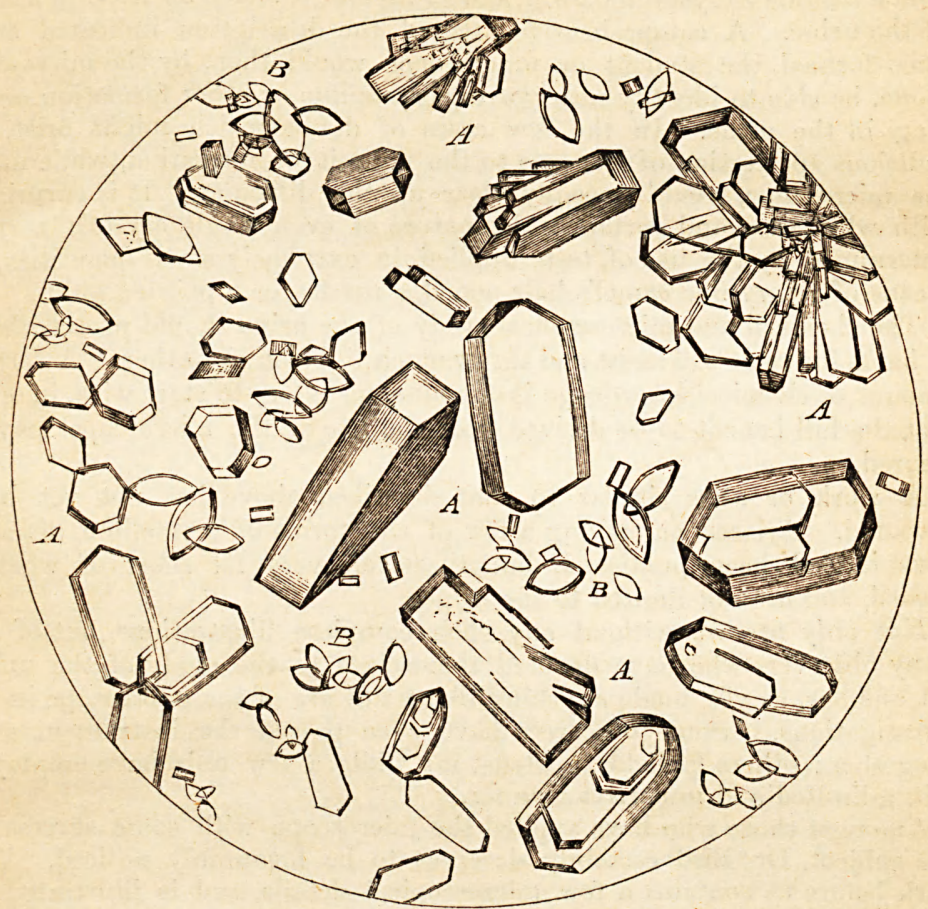

Creatinine from a few drops of human urine, allowed to evaporate spontaneously on a slip of glass. $A, A$. Crystals of creatinine; $B, B$. Crystals of uric acid. Drawn with the camera lucida, and magnified 100 diameters.

actively engaged in the treatment of disease, and who, consequently, ought to possess an accurate acquaintance with the subject; it must still continue, as at present, to be for the most part confined to a few individuals who devote themselves specially to it. When, however, the application of the microscope to this subject is fully and rightly made and understood, this will no longer be the case, and every medical practitioner will be able to determine for himself, in a few minutes, by means of that instrument (aided in some cases by reagents), the nature of the chief constituents, normal and abnormal, contained in any urine.

This correct and extensive application of the microscope has, however, yet, to a great extent, to be made; and the difficulties in the way of such an application are, in some respects, very great, but by no means insuperable. For this purpose it is requisite that a large number of figures be prepared, accompanied with full descriptions. These figures should be most carefully outlined with the camera lucida, coloured after nature, and 
drawn, as far as practicable, to a uniform scale. They should exhibit every chief variety and modification in the form, size, and colour, of not merely those salts and substances which subside as deposits, but also those which assume a crystalline form, and so become revealed on the evaporation of the urine. A comprehensive atlas of the description indicated being once formed, the student or practitioner would then, by the microscope alone, be able to identify nearly every crystalline or other formation occurring in the urine. In the few cases of doubt which might arise, the judicious application of reagents to the deposit or formation, while under the microscope, would speedily clear up the difficulty. It is surprising with what ease and certainty the nature of even single crystals may be determined by the use of tests applied, in extremely small quantities, by means of a very fine camel's hair pencil, a needle, or a pointed quill.

The chemical and microscopical study of the urine should proceed hand in hand, for each will assist and throw much light on the other. A certain amount of chemical knowledge is of course necessary to start with, in order that the full benefit to be derived from the use of the microscope may be secured.

A work or atlas similar to that described above has not yet been executed. Atlases portraying a few of the forms of crystalline deposits have indeed been published, but these fall very far short of what is needed, and are not limited to the urine.

Not only are we without any such complete illustrations, but of the many observers who have devoted themselves to the study of the urine, not one has, as yet, made anything like a full use of the microscope in his investigations. Some observers have even passed the instrument over altogether; others foolishly mistrust it; while a few only have employed it in a limited and imperfect manner.

Amongst those who have applied the microscope with some success to this subject, Dr. Bird certainly deserves to be favourably noticed. The work before us contains a few microscopical details, and is illustrated by sixty-one small woodcuts; a number, however, which is wholly insufficient to convey any idea of the great variety in the characters of the crystalline formations which are found in the urine. Moreover, these illustrations are rough diagrams, rather than complete and artistic drawings.

The want of complete and instructive figures, executed with every advantage of form and colour that can be obtained, has often forcibly struck us, and in the hope of one day or other being able to supply this desideratum, we have been for some years engaged in having accurate illustrations made of all the chief modifications of the various crystalline and other deposits met with in the urine. The number already executed amounts to about two hundred and fifty, and it is calculated that nearly one hundred more will be required to make up the series.

We have dwelt thus long on the application of the microscope to the study of the urine, because we are satisfied that its importance is in general by no means fully appreciated. The microscope should be used in the examination of every urine; not only should the urine be examined when it contains a visible deposit, but even when there is no apparent precipitate; since the deposit may be too small to be seen by the naked eye, or the crystals themselves forming it may be exceedingly minute. 
Not only should the urine at the bottom of the vessel be examined, but the surface of the fluid should be carefully looked to, as well as the sides of the glass in which it is contained. Moreover, the urine should be kept for some days, and submitted to microscopical examination from time to time, as precipitates and other formations or developments frequently present themselves, even many days after it has been passed. In this manner much valuable information, procurable in no other way, is constantly obtained.

Chapter II. is devoted to the subject of the "Physiological Origin and Physical Properties of the Urine." It treats of the metamorphosis of tissue, the density, colour, and consistence of the urine, with the amount of solids contained in it. The subject of the metamorphosis of tissue is ingeniously discussed and considered. It should be understood that the indications afforded by the tables given by Dr. Bird, calculated from the formula of Dr. Christison, and professing to show the amount of solids contained in any urine according to its specific gravity, are correct only within certain limits; this is well shown by Dr. Bence Jones, in the remarks which follow:

"Tables have been constructed, professing to tell how much solid matter is contained in urine of any specific gravity. It is said, that by taking the specific gravity, and referring to the table, the quantity of solid matter may be immediately determined. If the urine were simply a solution of one substance-as, for example, urea in distilled water-such tables could be made to give the truth; but when many different substances are dissolved in water, no tables can be trustworthy. A small quantity of one substance may increase the bulk of the urine more than a larger quantity of another substance; or equal quantities of different substances may increase the bulk of equal quantities of water in which they are dissolved to a very different degree; so that the solid residue in each might be equal, while the specific gravities of the solutions might be different. Experiment proves this in the case of the urine. There is no short road to any accurate results. The acid urine must be carefully evaporated, at a very low temperature, in the vacuum of the air-pump, over sulphuric acid, until, on being weighed and reweighed, it ceases to lose weight. If the urine be not acid, the result will be worthless. The following experiments were thus made on the specific gravity and solid residue of the urine before and after dinner. About 500 grains of urine were in each case evaporated.

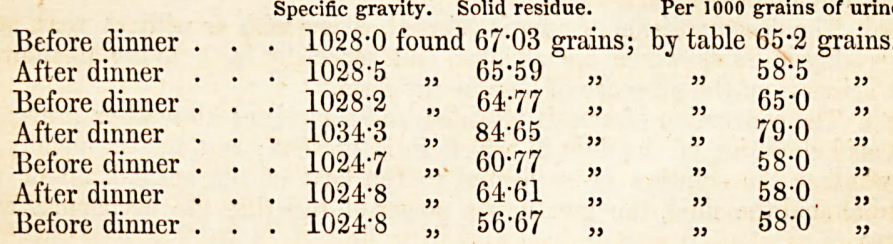

These experiments show that the quantity of solid contents cannot be determined by taking the specific gravity."

At page 46 is a useful table, by Mr. Ackland, of Hatton Garden, for reducing the indications of a glass urinometer to the standard temperature of $60^{\circ}$ Fahrenheit. This is the only new matter contained in the second chapter.

The chapter concludes with an account of the optical properties of urine containing sugar. In the application of the polariscope to the detection 
of this substance in the urine, many difficulties have to be overcome; and then the test is of use only where a large quantity of sugar is present, in which case more simple and certain tests are at our command.

Chapter III. treats of the "Chemical Physiology of the Urine;" under which head the physiological origin of its more important constituents is considered. At page 80 the following remarks occur, on the decomposition of urea into carbonate of ammonia:

"The mere act of boiling the urine is sufficient to convert a portion of urea into an ammoniacal salt; and by long keeping even in close vessels a similar change occurs. The rapidity with which this conversion is effected varies remarkably in different specimens of urine. I have known urine become alkaline within an hour of its emission; and yet, in one instance, I detected urea in a specimen of urine which had been preserved in a closely-stopped bottle upwards of ten years. The presence of a mucoid body in a state of change, acting as a ferment, certainly explains the rapid conversion of urea into carbonate of ammonia in some urine."

In the 9th Lecture by Dr. Bence Jones, on Animal Chemistry, page 90, we meet with these observations on the transformation of urea:

"Pure urea may be kept dissolved in distilled water, or it may, as you see in this test-tube, even be boiled without being changed into carbonate of ammonia; but if a few drops of ammoniacal urine, or a small quantity of mucus, is added, decomposition begins. By careful experiments more may be made out on this subject than the general fact, that some substance in a state of change is requisite to cause the change in the urea to begin; and the influence of the monads and vibrios, which are sometimes found in acid urine, may be determined."

It will be perceived that the statements of Drs. Bird and Jones on this point are in direct opposition; and as it appeared one of importance, we some time since instituted certain experiments, with a view to determine, more fully and accurately than had yet been done, the conditions which regulate the conversion of urea into carbonate of ammonia. The principal conclusions arrived at were as follow:

"lst. The simple act of boiling an aqueous solution of urea is sufficient to determine the gradual dissolution of that substance, and its conversion into carbonate of ammonia.

" 2 nd. This conversion of urea takes place, after a time, in distilled water, even without the aid of the spirit-lamp.

" 3 rd. The decomposition of urea is effected, either with or without heat, much more readily in fluids which are alkaline, and especially in those the alkalinity of which arises from the presence of lime in any form.

" 4 th. The conversion of urea is retarded, and sometimes altogether prevented, by an acid condition of the fluid in which it is present; and this is equally the case whether the solution be subjected to the heat of the spirit-lamp or not. The more acid the fluid, the greater its power of resisting the decomposition of the urea.

" 5 th. Animal matter, in a state of decomposition, exercises a powerful influence over the transformation of urea; and this it does partly by producing an alkaline condition of the fluid in which the two substances are contained, the alkalinity being produced by the carbonate of ammonia generated during putrefaction."**

It is always desirable, when the statements of authors are opposed, as in the present case, to point out the differences, and to ascertain, if possible, which are correct. Conflicting statements, occurring in different

* Lancet, vol. i. June 12, 1852, p. 567. 
works on the same subject, are calculated to puzzle and mislead the reader, who is not, in all cases, himself in a position to decide between them.

At pages 83 and 84, under "Uric Acid," we find these remarks :

"The deposits most frequently occurring in the urine on cooling, by evaporation in vacuo, or exposure to a freezing mixture, are, however, neither crystalline, nor composed of uric acid alone. They consist of urate of ammonia, sometimes mixed with urate of soda or lime, more or less contaminated with colouring matter; are amorphous, and readily dissolve in warn water, which scarcely acts on uric acid. We are hence compelled to seek for another explanation of the proximate formation of these deposits; and this, I believe, is found in the action of uric acid on the microcosmic salt, or double phosphate of soda and ammonia, which salt, or its elements, may be regarded as a constant constituent of healthy urine. When uric acid is mixed with a warm solution of this triple phosphate, urate of ammonia is formed, and phosphoric acid evolved, either free or combined with a base, and forming an acid salt. This urate of ammonia is not decomposed on cooling, but is simply deposited in delicate microscopic needles, readily redissolving on the application of heat, if sufficient water is present. On the addition of urine to a hot solution of these minute needles, they are deposited on cooling, combined with the colouring matter of urine, completely amorphous, and presenting all the characters of the commonest forms of urinary deposits. If, after the separation of the urate of ammonia, a fresh quantity of uric acid be heated in the supernatant fluid, more of the ammoniacal salt is formed, up to a certain point, when phosphate of soda yields, and urate of soda is generated, which on cooling is decomposed in the manner already described.

"I therefore ventured, some time ago, to propose the following as a probable explanation of the mode in which uric acid exists in healthy urine. Uric acid, at the moment of separation from the blood, comes in contact with the double phosphate of soda and ammonia, derived from the food, forms urate of ammonia, evolving phosphoric acid, which thus produces the natural acid reaction of urine. If the whole bulk of the urine be to the urate of ammonia formed not less than about 2701 to 1 , the secretion will, at the ordinary temperature of the air, remain clear; but if the bulk of fluid be less, an amorphous deposit of the urate will occur. On the other hand, if an excess of uric acid be separated by the kidneys, it will act on the phosphate of soda of the double salt, and hence, on cooling, the urine will deposit a crystalline sediment of acid sand, very probably mixed with amorphous urate of ammonia, the latter usually forming a layer above the crystals, which always sink to the bottom of the vessel.",

These observations are ingenious, but certainly are not altogether correct. That uric acid is present in urine, in combination with a base, or bases, is certain; but that base does not consist, as Dr. Bird and some others suppose, almost exclusively of ammonia. Lehmann most distinctly asserts, that what is usually described as urate of ammonia is indeed urate of soda. We find, at page 214 of Lehmann's 'Physiological Chemistry,"* the following observations in relation to this point:

"The sediment which is deposited from acid urine in fever, and in almost all diseases accompanied with fever, has long been misunderstood in reference to its chemical composition. Originally, it was regarded as a precipitate of amorphous uric acid, and subsequently (and almost to the present time) it was regarded as urate of ammonia. It has, however, been fully demonstrated, both by myself $†$ and Heintz, that this sediment consists of urate of soda, mixed with very small quantities of urate of lime and urate of ammonia.

* Translation, by Dr. Day.

+ Jahresber., d. Phys. Ch., 1844, $\$ 26$.

† Müller's Archiv., 1845, pp. 230-261. 
"It would be both superfluous and wearisome to recapitulate the arguments adduced by Becquerel, myself, and Heintz, against the opinion of Bird, who maintains that this sediment is always urate of ammonia, as the actual nature of the deposit has been so completely established. I will here only remark, that as I long ago found, and as Liebig has since confirmed, scarcely any ammonia occurs in urine, and that according to the direct analysis of the sediment made by Heintz, scarcely $1 \frac{0}{0}$ of ammonia could be found in it."

Farther on, at page 216, Lehmann proceeds to observe:

"Even in alkaline urine it is very seldom that urate of ammonia occurs as a sediment: in these cases it is found in white opake granules, which, as has been already stated, when seen under the microscope, appear as dark globules, studded with a few acicular crystals. It scarcely ever occurs except in urine which, by long exposure to the air, has undergone the alkaline fermentation. Even in the alkaline urine of patients with paralysis of the bladder, dependent upon spinal disease, it is very rarely that I have found these clusters of urate of ammonia. In the alkaline urine that is sometimes passed, in other conditions of the system, it is never found."

It is of much importance that the chemical constitution of the urates occurring in the urine should be correctly determined, and considerable difference of opinion being still entertained on this point, we have instituted certain qualitative and quantitative analyses of different specimens.

\section{Analysis of First Specimen.}

Colour, bright rose-red. Under the microscope it was found to consist of minute amorphous particles, which dissolved in warm water, and re-appeared on cooling in their original state. Acetic acid slowly developed a multitude of rhombic crystals of uric acid.

The filter containing the deposit was treated with half an ounce of cold water in three portions. This removed a quantity of urea and a little of the urate. It was then drenched with boiling water, and the filtered liquid allowed to stand for twenty-four hours. The deposit was collected and dried at $70^{\circ} \mathrm{Fahr}$. It weighed three grains.

One grain was dried at $212^{\circ}$, by which means it lost 0.07 of moisture. This was afterwards incinerated, and it furnished 0.092 of a white ash, which was very alkaline to turmeric paper, though not permanently so; it was infusible before the blowpipe, but tinged the flame of a violet white colour. When dissolved in acetic acid, and tested with oxalate of ammonia, it gave a precipitate of oxalate of lime.

One grain was distilled with two drachms of weak potash, and it gave an alkaline liquid which contained 0.012 of ammonia. While boiling, the potash solution acquired a bluish green colour, showing the presence of uramile or murexide, substances which doubtless gave the rose-red tint to the precipitate.

One grain was treated with one drachm of weak acetic acid, by which means 0.66 of nearly colourless uric acid were obtained; the acetic solution gave a copious precipitate with oxalate of ammonia.

These results prove that the precipitate consisted of bi-urate of lime, with a little bi-urate of ammonia, and a still smaller quantity of bi-urate of potash, together with colouring matter. The following is the per-centage composition : 


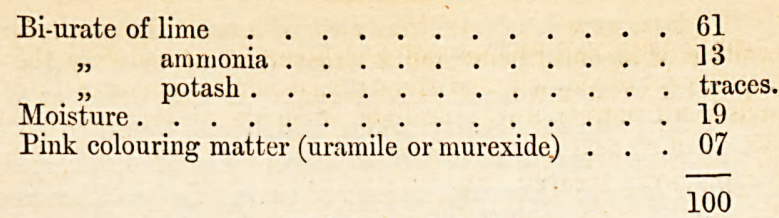

Analysis of Second Specimen.

The colour was at first of a bright rose-red, but after washing with cold water it lost a great deal of its colour, and became of a foxy or yellowish red tint.

In its treatment with reagents it gave the same reactions as the last, and furnished very nearly the same proportions of the several products. Its per-centage composition was,

$$
\begin{aligned}
& \text { Bi-urate of lime . . . . . . . . } 70
\end{aligned}
$$

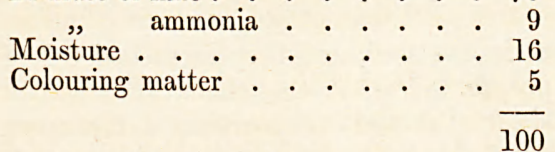

The solutions from which the preceding were deposited, after cooling, were evaporated to dryness at a temperature of $100^{\circ}$ Fahr., and on examination they were found to contain a very small quantity of urea, together with bi-urate of lime and a little bi-urate of ammonia, but no urate of soda.

\section{Analysis of Third Specimen.}

The urate, as it appeared when diffused through the urine, which was of a deep brown colour, was of a pale, fawn-tint; but when collected on the filter it was of a light rose pink. After some hours this colour disappeared, and the urate became of a greenish hue, to the eye resembling somewhat purulent matter. On submitting a portion of the urate in this state to the microscope, it was seen that it had lost its usual granular form, and had become aggregated into small, globular, crystalline masses, of a very pale colour and deliquescent appearance. The alteration of colour observed was no doubt owing to this change in the form of the urate.

The ash of the incinerated urate amounted to about ten per cent.; it gave a permanent stain to turmeric paper, was soluble in water, and tinged the flame of the blowpipe of a violet colour, showing that it was composed chiefly of potash. 100 parts gave

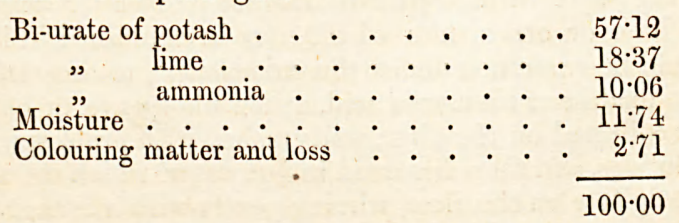

\section{Analysis of Fourth Specimen.}

This was of a bright deep pink colour, and was obtained from a urine having a specific gravity of 1024 , which, on the evaporation of a few drops 
on a slip of glass, gave a crystalline crust of urea. It was treated with a large quantity of alcohol, by which a great deal of urea and a very little amorphous pink matter were dissolved out. It was dried at a temperature of $70^{\circ}$ Fahr., and its density taken, which was found to be 1100 .

Ten grains were treated with half an ounce of cold water, and set aside for twenty-four hours: the water dissolved two grains, and became coloured of a pale, sherry-tint. When evaporated, it yielded a fawn-coloured deposit, which, on incineration, furnished 0.25 of a white ash, which was found to be lime.

Two grains were treated with two drachms of dilute acetic acid, which was allowed to act for twenty-four hours; by this means 1.2 grains of nearly white uric acid were obtained.

Two grains were dried for several hours over a steam-bath, and they lost $0 \cdot 2$ from escape of moisture. The remainder was then distilled with two drachms of weak liquor potassæ, and the distillate contained 0.04 of free ammonia.

Two grains were incinerated, and they furnished 0.2 of white ash: this was found to be potash.

These results show that the composition of the urate deposit was as follows :

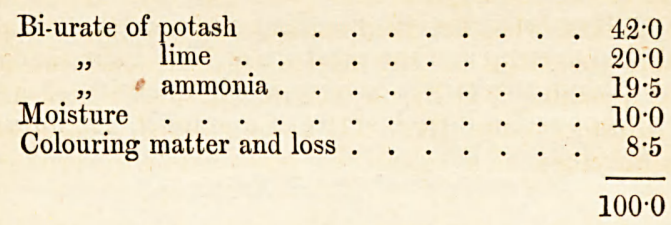

\section{Analysis of Fifth Specimen.}

Colour, dull pink. The ash which resulted from the combustion of this amounted to 12.5 per cent.; it was strongly and permanently alkaline, and tinged the flame of a full yellow colour, from which it is manifest that it consisted in great part of soda. The acetic solution was made slightly turbid by oxalate of ammonia, which shows that it also contained lime; when distilled with potash', ammonia was detected. 'This specimen, therefore, consisted in great part of urate of soda, but it likewise contained a small quantity of urate of lime, and probably, also, of urate of ammonia.

In making analyses of urates, it is absolutely necessary that certain precautions should be observed. The best mode of proceeding is as follows:

The filtering paper used should be digested in acetic acid, in order to free it from lime or other salts which may be contained in it. The precipitate should be examined under the microscope, to ascertain whether it be free from oxalate of lime, uric acid, triple phosphate, or other deposits. It should be collected on the filter, well washed with proof spirit to remove urea and chlorides, and then dissolved in.hot water, which should be poured upon the precipitate on the filter, stirring gently with a feather. Of course as the water becomes cold the urates are thrown down, when they may be collected and dried for analysis. If either triple phosphate or uric acid be present, the filter will retain these while the urates pass through; but if there be any oxalate of lime, there is danger that the crystals of this salt will pass through the filter, and so vitiate the analysis. 
It has now been proved, that the deposits considered by Dr. Bird and others to consist principally of urate of ammonia, have a variable composition, being made up of the urates of lime, potash, and soda, with very small quantities only of ammonia. From the very great difficulty which is experienced in freeing these deposits entirely from urea, it may be questioned whether the ammonia is not derived, in some cases at least, from the decomposition of that substance. It is, therefore, an error to regard the urates as consisting ordinarily of urate of ammonia. Dr. Bird, as already noticed, is not singular in his opinion; as most other observers in this country have taken a similar view of their composition; for example, Dr. Bence Jones, and the late Dr. Prout. By medical men in general they are almost constantly spoken of as urate of ammonia.*

The omission previously referred to, with respect to a formula for the separation of creatine and creatinine from the urine, is supplied in this chapter, and Liebig's process for obtaining those substances is given.

The only new matter contained in Chapter III., is a short reference to a paper by Dr. Lionel Beale, on the "Chlorides in Pneumonia."

Chapter IV. is on the "Chemical Pathology of Uric Acid and its Combinations." The urates of the urine are treated throughout as consisting of urate of ammonia, although in one place Dr. Bird refers to the recent researches of Heintz, who, Dr. Bird states, has found that they always contain appreciable quantities of the urates of lime and soda, and often of magnesia and potash. " "It by no means follows," writes Dr. Bird, "as assumed by Zimmermann, that this lime existed, combined with uric acid, as an admixture of a calcareous phosphate will produce the same reaction."

The results of Heintz's analyses of the urates are not correctly given by Dr. Bird; for that chemist found that they consisted chiefly of urate of soda, with very small quantities of the urates of lime, potash, and magnesia, and scarcely any ammonia. This conclusion of Heintz and Lehmann we have already shown to be correct, so far as the ammonia is concerned. The chief differences in the results of our investigations and those of Heintz and Lehmann are, that in many cases these deposits consist almost entirely either of urates of lime, potash, or soda, or of all these combined in various proportions.

The woodcuts illustrating modifications in the form of the crystals of uric acid, and the so-called urates of ammonia and soda, are the same as in the last edition of the work. The only additions to this chapter are notices of the artificial Vichy water of the Spa at Brighton, and of a secret remedy, known as "constitution water," which has acquired some celebrity in the treatment of calculous affections.

As no quantitative analysis is given by Dr. Bird of "Vichy water," and an incomplete one only of "constitution water," the following results of a chemical examination of these waters will not be without interest:

\section{Results of the Analysis of a Sample of the Artificial Vichy Water of the Spa at Brighton. By Dr. Letheby.}

The water is effervescent from free carbonic acid. It is alkaline to test paper; and it has a specific gravity of 1005. 2000 grains of it were

* It should be stated, that in the above analyses of the urates we have received great and valuable assistance from Dr. Letheby. 
evaporated, and they yielded $9 \cdot 88$ grains of a very white saline residue, which consisted of-

$$
\begin{aligned}
& \text { Sulphuric acid . . . . . . . . . . . 034 } \\
& \text { Chlorine . . . . . . . . . . . } 070 \\
& \text { Carbonic acid . . . . . . . . . . } 5393 \\
& \text { Soda . . . . . . . . . . . } 4 \cdot 19 \\
& \text { Potassa . . . . . . . . traces } \\
& \text { Lime . . . . . . . . . : } 034 \\
& \text { Magnesia . . . . . : } 0.18 \\
& \text { Silica and alumina } . . \quad . \quad . \quad . \quad 012 \\
& 9 \cdot 88
\end{aligned}
$$

\begin{tabular}{|c|c|c|c|c|c|c|c|c|}
\hline Bicarbonate of soda & & & $\begin{array}{c}1 . \\
\text { Source } \\
\text { Grande Gril } \\
. \quad 9 \cdot 80\end{array}$ & & $\begin{array}{c}2 . \\
\text { Source } \\
\text { Nouvelle. } \\
9 \cdot 68\end{array}$ & & $\begin{array}{c}3 . \\
\text { Source } \\
\text { Prè-Salé. } \\
9 \cdot 40\end{array}$ & $\begin{array}{l}4 . \\
\text { Nouvelle Source } \\
\text { Célestines. } \\
\ldots \quad 8 \cdot 27\end{array}$ \\
\hline ,,$\quad$ lime & & & $\begin{array}{l}0.21 \\
. \quad 0.21\end{array}$ & $\begin{array}{l}\cdots \\
\ldots\end{array}$ & $\begin{array}{r}9.68 \\
.18\end{array}$ & $\cdots$ & $\begin{array}{r}9.40 \\
.89\end{array}$ & $\begin{array}{r}8 \cdot 27 \\
.55\end{array}$ \\
\hline ", magne & esia & & $\cdot 13$ & $\begin{array}{l}\cdots \\
\cdots\end{array}$ & $\cdot 11$ & $\ldots$ & .81 & $\cdot 42$ \\
\hline ulphates of soda and & d potasl & & $\cdot 97$ & .. & $\cdot 82$ & $\ldots$ & 52 & $\cdot 38$ \\
\hline Silicate of alumina & t & & $\cdot 46$ & & $\cdot 46$ & $\cdots$ & $\cdot 14$ & (?) \\
\hline Alkaline chlorides & & & $\begin{array}{r}\cdot 80 \\
1 \cdot 08\end{array}$ & & $\begin{array}{r}.68 \\
1 \cdot 00\end{array}$ & $\cdots$ & .55 & .28 \\
\hline & & & $13 \cdot 45$ & & $12 \cdot 93$ & & $12 \cdot 91$ & $10 \cdot 66$ \\
\hline
\end{tabular}

These constituents may be arranged in two ways, thus:

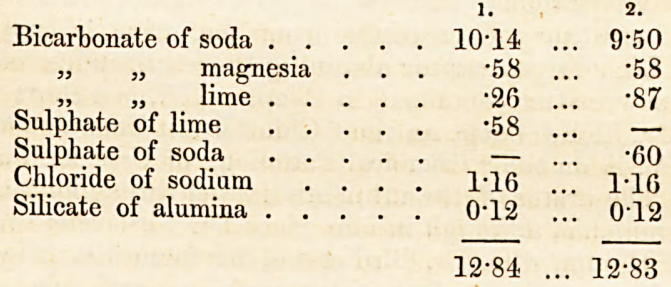

The first is the most probable arrangement of the elements; but the second form is introduced in order to show how closely this water resembles that from the wells of Vichy, examined by Henry in 1847. The following analyses are from his paper on the subject:

The water also resembles the alkaline springs of Cusset and Hauterine in France. In fact, there is but little difference in the composition of the alkaline waters of Vichy, Cusset, and Hauterine; and the artificial water from the Spa at Brighton is a very good imitation of all of them. It will be observed from these analyses, that the active ingredient in the whole of these waters is bicarbonate of soda. The dose of Vichy water is a small tumblerful two or three times a day, which equals, perhaps, about a pint - a quantity which contains $35 \cdot 5$ grains of bicarbonate of soda.

\section{Results of the Analysis of a Sample of "Constitution Water."}

Taste and feel soapy; specific gravity, 1031; very alkaline to turmeric, and reddened litmus paper; it effervesces briskly with acetic acid; gives a rather copious precipitate with nitrate of silver acidulated with nitric acid; 
gives a small precipitate with nitrate of baryta and nitric acid, and with oxalate of ammonia; it shows the presence of traces of alumina and silica; 400 grains of the water left, after evaporation, $12 \cdot 6$ grains of a white solid residue, which does not char by heat, but fuses into a clear globular mass before the blowpipe, and gives a violet tinge to the flame. It therefore contains 3.2 per cent. of common or impure carbonate of potash, or pearl-ash, which is always contaminated with chlorides, sulphates, and silicates, with a little lime and alumina.

The dose of constitution water is the eighth part of a bottle about the size of a wine-bottle, four doses to be taken daily, this being equal to about 184 grains, or upwards of three drachms, of carbonate of potash. The price is $62 s$. per dozen; its actual cost, exclusive of bottles, is not nearly as many farthings.

Furnished with the above recipe or analysis, the admirers of "constitution water" may supply themselves with it at a very much cheaper rate than at $5 s .2 d$. per bottle. The remedy is indiscriminately recommended in all cases of "strangury, gravel, and stone." The only cases to which it is really applicable are those of uric-acid diathesis. In some forms of urinary deposit and stone it would be productive of incalculable mischief, and therefore it should on no account be taken excepting under medical advice. Persons are too apt to imagine that there is some hidden charm in these secret and empirical remedies; for the removal of this delusion no method is so effectual as the publication of their actual composition.

The whole of the observations contained in this chapter relating to the treatment of uric-acid diathesis are sound, practical, and of much value.

From the researches of Seguin and Anselmino it appears, that the amount of organic matter exhaled by the skin in the course of twentyfour hours is $107 \cdot 47$ grains. In commenting upon this, Dr. Bird writes, "It may be cafely assumed, that when the skin is unable to perform its functions, the $107 \cdot 47$ grains of organic matter, which then lose their proper outlet, appear wholly or partly in the urine in the form of urate of ammonia."

It is, of course, a very rare circumstance for the whole skin to be incapable of performing in some degree its emunctory functions, and therefore the whole quantity of organic matter above referred to, would scarcely, in any case, be thrown upon the kidneys for elimination; neither could so large an amount of organic matter escape from the system wholly in the form of urate of ammonia, since the quantity of this urate contained in the urine is in general so small, and falls so very far short of what would be necessary, in order to bear out the remarks of Dr. Bird.

Chapters V., VI., VII., and VIII., are devoted to the consideration of "uric oxide, purpurine, cystine, and hippuric acid:" no additions have been made to any of these chapters; they remain as in the previous edition.

Chapter IX. is devoted to the consideration of oxalate and oxalurate (?) of lime.

This is the most original chapter in the work: Dr. Bird was the first to detect the frequent presence of oxalate of lime in the urine in a 
crystalline state, and to show its importance in a pathological point of view.

The views of Dr. Bird with respect to the pathology of oxalate of lime have met with a good deal of opposition, and it may therefore be well to bestow some consideration on this point, and to endeavour, from the facts already in our possession, to draw a definite conclusion. Dr. Bird, in the opening paragraphs of the chapter, thus refers to the diversity of opinion which exists as to the importance of deposits of oxalate of lime.*

"Oxalate of lime is so frequently present in the urine, is often a constituent of one of the most annoying forms of calculous concretions, and is generally so important in its pathological bearings, that it merits especial attention, and $I$ am now particularly anxious to allude to the importance of carefully studying the relations of this form of deposit to certain states of health, because it seems now to run some risk of being tossed aside as a thing of no consequence. A curious revulsion of feeling seems to have taken place, amongst some at least, on this subject. When I first discovered oxalate of lime as a crystalline deposit, and announced its frequency, my observations were doubted by many, and whenever they were favoured by any attention, they were always distinctly stated to rest exclusively on my authority. Now that more extended observations have demonstrated the truth of my statements, we are told, both in this country and abroad, that oxalate of lime is of constant occurrence, and of no importance - a remark to which too many sufferers from this diathesis can give a melancholy denial."

Amongst those who have doubted the importance of the occurrence of oxalate of lime in the urine, may be mentioned more particularly, Lehmann and Bence Jones.

"Experience," observes Lehmann, "at the bed-side, teaches every unprejudiced observer that the appearance of oxalate of lime in the urine is by no means accompanied by the group of symptoms which certain English physicians describe as pertaining to what they call the oxalic diathesis."

And again, farther on, Lehmann remarks-

"It seems, moreover, unreasonable to set up such a diathesis, since the establishment of a special disease from a single symptom - that symptom being only the occurrence of oxalate of lime-is entirely opposed to the spirit of rational medicine." $\dagger$

Dr. Bence Jones, in his seventh lecture, has the following remarks on the subject :

"Oxalate of lime is so frequently found in the urine of those who are in a good state of health, that I do not consider it as indicating any disease, but only a disorder of no serious importance. It scarcely indicates a more serious derangement of the general health than a deposit of urate of ammonia does. It may occasionally be found in the urine of all who lead sedentary lives, taking insufficient air and exercise, and more food than is requisite for the daily wants of the system. I have found it in the urine of those who are free from every complaint. Even in the urine of healthy children it may frequently be seen. I have met with it in every kind and stage of disease. In the fracture wards of St. George's Hospital I have very frequently found it. The most severe case I ever saw, was an artist, aged 30, dying of abdominal aneurism. In cases of indigestion, especially where flatulence occurs; in cases where no indigestion ever was felt; in skin-diseases; in cases where the skin never was affected; in cases of acute rheumatism, of acute gout, of fever; in sciatica in a gentleman 74 years old, with spermatorrhea; and in the diseases of women and children, octahedral crystals occur." $\neq$

* Loc. cit. p. 207.

$\dagger$ Translation, by Dr. Day. pp. 46, 47 .

$\mp$ Loc. cit. p. 63 . 
Because oxalate of lime is not unfrequently present in cases where no obvious or special disease exists, as we all know to be the case, it by no means follows, as a necessary consequence, that the occurrence of these deposits is not under any circumstances a matter of serious importance. Nothing is of more frequent occurrence than deposits of uric acid, the urates, triple phosphate, \&c. ; yet it would scarcely be logical to conclude from that circumstance alone, overlooking a variety of other considerations, that these deposits were of no pathological importance. The detection of oxalate of lime in the urine, where no well-marked evidence of disease or derangement exists, shows simply we must not conclude, in all cases, that its presence is indicative of serious morbid derangement. It shows merely the necessity for carefully discriminating between those cases in which oxalate of lime is present from the nature of the food taken, and is merely temporary, and those in which it is connected with evident disordered function or disease, and in which also the deposit is persistent. Some of the coustituents of the urine, the persistent presence of which in undue quantity is regarded by all as affording sufficient evidence of either disease or disordered action, are proper to healthy urine; now this can scarcely be said to be the ease with oxalate of lime. Again, the condition of the urine, which, continuing for a lengthened period, ends in one of the worst forms of calculus, - viz., that of oxalic calculus, - cannot surely be regarded as a matter of no serious importance. Oxaluria, or the oxalicacid diathesis, in the same way as are the other diatheses, is characterized by certain symptoms more or less peculiar, and these are well described by Dr. Golding Bird.

A few remarks upon certain modifications in the form of the crystals of oxalate of lime may next be offered. The ordinary form, as is well known, is that of the octahedron, but this presents certain peculiarities which have not been well described; thus the crystal is not an ordinary octahedron, with equal angles, but is a compressed or flattened octahedron. When the crystals are small and immersed in fluid, they lie, for the most part, with their summits more or less directed towards the observer (fig. $4, A)$; but when large, many of them frequently lie upon their sides, and then present the appearance of elongated rather than compressed octahedra (fig. $4, B$ ), and as such they have been often described and figured. This appearance is, however, entirely deceptive, as is readily seen when the crystals are rolled over. The form of the octahedron of chloride of sodium is the very reverse; in place of being compressed, it is elongated, in consequence of which it always lies upon its side. This difference in shape affords a ready means of discriminating with the microscope alone these two salts from each other.

In another modification of the octahedron of oxalate of lime, the facets are excavated and the angles produced or thrown out a little, so that the crystals appear somewhat cruciform (fig. $4, D$ ). This form of octahedron invariably occurs when oxalate of lime is artificially prepared by pouring a solution of oxalate of ammonia into lime-water.

A third, and one of the most remarkable varieties of the octahedron, is that in which the angles of the crystals run out, so as to form a four-rayed star (fig. $4, C$ ); this variety is the largest and most beautiful of all the crystalline forms of oxalate of lime which have as yet occurred to the 
reviewer; it presented itself in the urine, together with other modifications, after a large dose of binoxalate of potash. There are still, however, other modifications of the octahedron. One of these consists of a quadrangular prism, terminated by the ordinary pyramidal summits (fig. $4, E$ ); this variety, together with the preceding, was described by the reviewer in the 'Lancet' of Feb. 9th, 1850. The description there given of the prismatic variety is as follows:- "A second very distinct modification is that in which a short quadrangular prism is interposed between the quadrangular pyramids, of two of which each octahedron is composed."* The above form is sometimes further modified by the truncation of the pyramidal summits; indeed, the two modifications often occur in the same specimen. We have met with them in the urine both of the horse and of man.

The form of dumb-bell crystals of oxalate of lime is also not in general well understood or described. The enlargements forming the heads of the dumb-bells are not usually globular, but are flattened, so that the crystals seen on one surface appear narrow in the middle, and broad at each end; while in the side view they are altogether narrow, the neck even being, in some cases, the thickest part. Each dumb-bell formation, as was also pointed out in the communication above referred to, should therefore be studied under different views, front, side, and end views, otherwise no very clear or definite idea of its true shape can be obtained. In the same communication, the following modifications of dumb-bell crystals of oxalate of lime were thus briefly noticed:

"The dumb-bell form ordinarily met with is of a very regular shape and size, has a smooth and equal outline, is distinctly striated, and while its front surface is broad, its side is narrow and compressed, with a slight central enlargement, corresponding with the neck which joins the two halves of each dumb-bell together. (Fig. 4, F.)

"The first modification of the above typical form is of equal size with the former, is not flattened and compressed, but its side and end surfaces are nearly as broad as in the front view; the striæ are but just apparent. (Fig. 4, G.)

"A second variety, smaller than either of the above, has the side also nearly as broad as the front view; the neck of each dumb-bell is thick and protuberant, and the dilated extremities are furnished with short tail-like appendages. (Fig. $4, H$.)

"A third form, rather smaller than the preceding, has the front surface of an oval shape; this surface appears excavated or indented, while the side surface is narrow, but presents an obvious dumb-bell outline. (Fig. 4, I.)

"A fourth variety is ellipsoidal, the dumb-bell formation being in many cases traceable within the ellipse; it is also in general of but small size. (Fig. $4, K$.)

"This variety, which approaches very closely to the preceding, was first pointed out to me by Dr. Griffith, from whose preparation I have an accurate drawing; I have since observed it, presenting very nearly all the same characters." +

The modifications of the octahedron with the quadrangular prism, and also the oval variety of the dumb-bell, were figured for the first time in the third edition of ' Urinary Deposits,' published in 1851. Dr. Bird does not, however, refer to our previous descriptions of these varieties, nor to any of the other modifications then described. The whole of the above-noticed modifications are represented in the accompanying wood-engraving. 
Fig. 4.
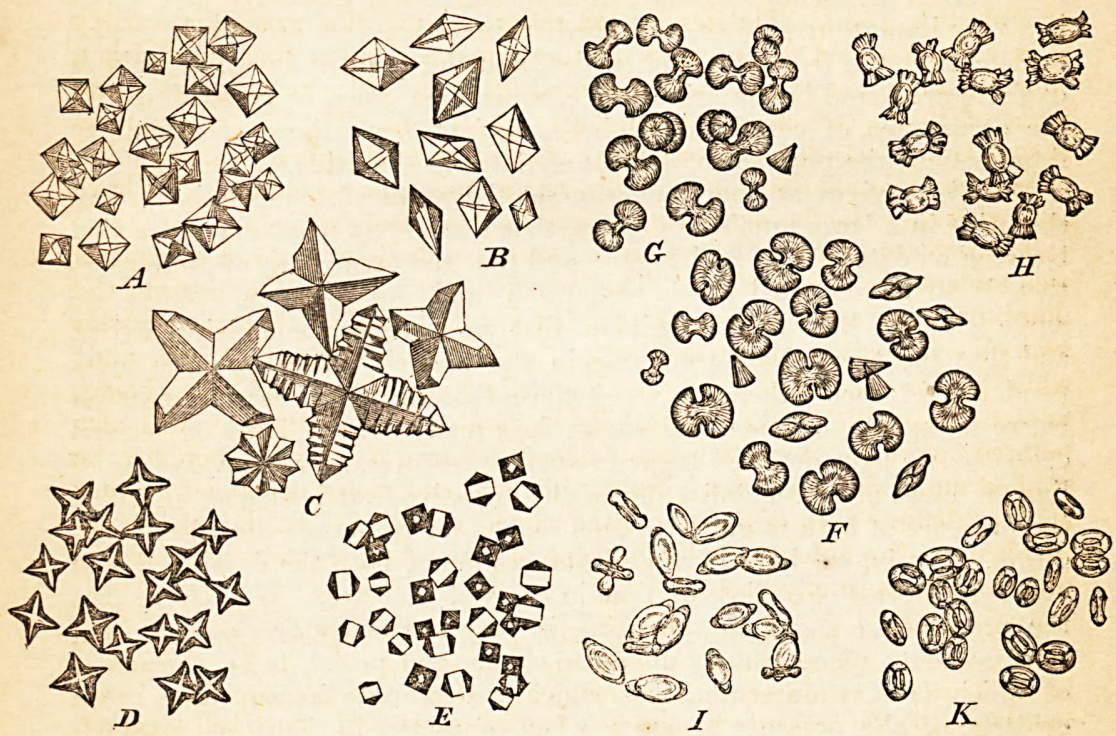

Modifications in the form of the crystals of oxalate of lime, all, with the exception of $D$, from human urine. $A$, Ordinary form of octahedra; $B$, Octahedra apparently elongated; $C$, Octahedra with the angles run out so as to form crosses and stars; $D$, Octahedra with the angles somewhat produced, formed artificially, magnified 420 diameters; $E$, Octahedra with a quadrangular prism interposed between the summits; $F$, Ordinary form of dumb-bell crystals, the crystals being flattened; $G$, Dumb-bells not flattened, having globular heads; $H$, Dumb-bells with tail-like appendages; I, Dumb-bells having a somewhat oval form, as seen on the front view ; $K$, A somewhat similar modification of the dumb-bell crystals of oxalate of lime. Drawn with the camera lucida, and magnified 220 diameters.

Dr. Bird, as have other observers, refers to the fact, that oxalate of lime sometimes crystallizes in the urine after the lapse even of some hours, and this, also, where no crystals were present when first passed. This shows the necessity of not at once concluding, from the absence of crystals on the first examination, that oxalate of lime is not present. The most remarkable instance which we have met with, of the formation of these crystals after the urine was passed, is the following:-Two samples of urine, the one morning, and the other after-dinner urine, both being perfectly free from crystals of oxalate of lime, were set aside for some days; in the course of a week or so, a dense stratum of penicilium glaucum, in full fructification, formed on each urine; the underneath surface of this stratum, and the sides of the glass in which the urine was contained, was found to be covered with myriads of fine octahedral crystals of oxalate of lime, which adhered to and were entangled in the threads forming the thallus. Now this stratum must have taken, at the least, six or seven days 
for its growth, and consequently, nearly the same time must have elapsed before the crystals of oxalate of lime were formed.

At page $224 \mathrm{Dr}$. Bird refers to the occurrence of oxalate of ammonia, or of some other soluble oxalate, in urine containing oxalate of lime. This is a very important subject, and further investigations are much needed to determine the frequency with which, and the quantity in which, soluble oxalates are found in the urine. We, some time since, in connexion with the occurrence of certain dumb-bells, distinct from those of oxalate of lime, noticed the presence of soluble oxalates in the urine.*

Dr. Bird arrives at the conclusion, as the result of his examination of the urine in a large number of cases, that there is no necessary connexion between oxalate of lime and sugar; and that the occurrence of these together is to be regarded as the exception, and not the rule. While we agree with Dr. Bird in the opinion that no necessary connexion exists, and that the two substances occur in the majority of cases, quite independently of each other, we yet believe that in certain cases a relation between oxalate of lime and sugar does really exist. Thus on several occasions we have detected sugar in small quantities, as well as oxalate of lime, in cases of extreme disorder of the digestive functions, and in which the presence of both might have been looked for from such disordered condition. Again, we have in some instances found both the dumb-bell and octahedral forms of oxalate of lime in cases of diabetes. We believe that the presence of sugar in the urine is very frequently overlooked, from reliance being placed chiefly upon the copper and potash tests, the action of which is very uncertain, and which will scarcely in any case afford evidence of the presence of sugar when contained in the urine in small quantities only.

Chapter X. treats of the "Chemical Pathology of the Earthy Salts."This is one of the least perfect and satisfactory chapters in the whole book, no additions having been made to it since the last edition; the only alkaline and earthy phosphates described are the ammonio-phosphate of soda, phosphate of magnesia, and phosphate of lime.

The presence of ammonio-phosphate of soda, as a constant constituent of normal urine, is by no means well established; whereas, it has been clearly shown, that the neutral phosphate of soda and acid phosphate of soda are constant constituents of the healthy urine. These alkaline phosphates are not described or referred to by Dr. Bird. A very excellent account of these salts is given in the recent and voluminous work of MM. Robin and Verdeil: these authors give the following directions for obtaining the neutral phosphate from urine : $\dagger$

"When we decant the fluid from highly concentrated urine, to separate the saline deposit and add to it absolute alcohol, there is deposited slowly upon the sides of the vessel, crystals of neutral phosphate of soda. These are plates derived from the rectangular or right rhombic prism with truncation of the edges.

"Sometimes these plates are irregular, and striated upon their surfaces, in different ways. They polarize light; the last forms, particularly, give colours most remarkable for their tint and intensity.

"It is easy, with a little practice, to distinguish these crystals from all other

* Lancet, 1850, vol. i. p. 177.

† Traité de Chim. Anatom. et Physiolog. vol. ii. p. 333. 
kinds in the urine, and above all, from the acid phosphate, which we shall describe further on."

On the extraction of the acid phosphate of soda from urine MM. Robin and Verdeil have the following remarks :*

"The acid phosphate of soda may be obtained crystallized in the urine, by following the same course which we have indicated in treating of the neutral phosphate of soda. When this is crystallized, there is deposited, three or four days after, crystals much more soluble in water than the neutral salt; we may hasten the deposit by adding ether to the liquid already treated with absolute alcohol. These crystals, from the mode of truncation of their angles, or the sides of the base, appear to be derived from the rectangular or right rhombic prism. The truncation usually marks almost the whole of the base.

"The forms of these crystals vary but little, they are either prisms or plates. These crystals are very transparent, and their faces cannot be well observed, but as we see them turn upon themselves under the microscope, borne by a current of liquid. Moreover, as these crystals are generally deposited against the sides of the vessel, to which they adhere, it is rare to find them well formed; they are flat, and incompletely formed on the adherent side."

Figures are given showing the forms of the crystals of both these salts.

The varieties in the forms of the crystals of ammonio-magnesian phosphate are described by Dr. Bird, under the heads of prisms, stellæ, penniform crystals, and stellar and foliaceous crystals.

The penniform crystals described by Dr. Bird unquestionably consist, for the most part, of phosphate of lime, as was long since pointed out by the reviewer. This statement is founded upon an examination of the specimen from which the figure given by Dr. Bird was made, as well as upon repeated chemical analyses, both by Dr. Letheby and ourselves. The forms as well as the chemical characters of these crystals differ entirely from those of triple phosphate; viewed with a low power of the microscope, from being broad at one end and narrow at the other, they appear wedge-shaped; but under a higher power they are seen to be really six-sided prisms. Although they occur sometimes singly, they yet usually form more or less complete rosettes and stellæ, resulting from the union of several crystals, by their narrow, pointed extremities. They occur usually in urine which is somewhat acid, and not until after it has been voided some time: in several of the cases in which they have fallen under our own observation, the diabetic torula has become developed in the urine, showing the presence of sugar. $\dagger$

Dr. Bird does not refer to the occurrence of phosphate of magnesia in the urine, except in combination with ammonia ; nevertheless, there is no doubt that this salt does sometimes occur in a crystalline state, in a form and condition very different from that presented by any of the ordinary varieties of triple phosphate. It has been stated by MM. Robin and Verdeil to be commonly present in a crystalline condition in the urine of domestic rabbits, which owes its troubled aspect to this salt. We have met with phosphate of magnesia in human urine, alkaline from fixed alkali. $\neq$

Neither does Dr Bird describe phosphate of lime as occurring in the urine in a crystalline state, although it occasionally does so, as has been

* Loc. cit. vol. ii. p. 340.

+ Proceedings of the Royal Medico-Chirurgical Society, Nov. 1852.

$\mp$ Proceedings of the Medical Society, Jan. 1853; and also Lancet, April, 1853. 
already shown. Moreover, MM. Robin and Verdeil describe an acid phosphate of lime differing from that which we have noticed, in the form of its crystals, as well as, probably, in its chemical characters.

"We have met with this principle," these authors state, " in the urine of man, and in that of the dog. It is found in variable proportions, greater in the second than in the first, but we have not been able to determine accurately the quantity."

\section{Farther on, they remark-}

"The whole of the salt, of which we speak, contained in the urine, does not crystallize constantly. It forms on the surface of the liquid which one evaporates, an amorphous layer, which unites in groups the spherical blackish masses of urate of soda. When it crystallizes, which depends, no doubt, on the conditions of evaporation, it is always accompanied with this amorphous matter, which holds them united in groups with the urate of soda. The crystals have all the form of halfoctahedra, elongated, being derived from the right prism with a rectangular base. Some are large, others very small. They may be isolated like the preceding, but the most part are united, one to the other, in different ways, either two and two, or in larger groups. They are soluble in acetic acid.

"In the dog especially, when the urine is very acid, we find a great quantity of these crystals, of the same size as the preceding. There exist, at the same time, many very small, either isolated or grouped, forms.

"We meet with, moreover, more frequently than in men, forms having the disposition of lamellæ, isolated or grouped in different manners, and forming very considerable masses; many of these lamellated groups present the very regular form of half-octahedra elongated.

"These crystals are colourless, transparent, their edges well marked; the dihed: al angles are very sharp; they refract light but little; all these characters give them a hard aspect, almost mineral, which prevents them from being confounded with other principles."

The crystals of phosphate of magnesia, which we have described and figured, belong probably to neutral, or alkaline phosphate. We have reason to believe that the ordinary form in which phosphate of magnesia exists in the urine is that of acid phosphate, and that this, when the urine is evaporated, very readily crystallizes in prismatic triangular crystals. We once succeeded in obtaining them in sufficient quantity for a separate analysis; but before the actual composition of these crystals can be considered as finally determined, it will be proper that other analyses should be made.

The last earthy salt considered by Dr. Bird is carbonate of lime. The only remark we shall make in regard to this is, that it sometimes presents itself in the urine of the horse and rabbit in the form of dumb-bells. It is described and figured as occurring of the same form, by Dr. Otto Funke, $\uparrow$ in human urine, who, in remarking upon them, somewhat strange to say, states that he has never seen crystals of dumb-bell oxalate of lime in human urine. The dumb-bells occur mixed up with the ordinary spherical striated masses.

Chapter XI., treating of " Deposits of Abnormal Blue and Black Colouring matters," remains the same as in former editions. The occurrence of these coloured deposits in urine is of the highest interest, and we believe that

* Loc. cit., tom. ii. pp. $303,304$.

† Atlas, der Phys. Chem., Table 1, fig. 2. 
when they are rightly understood it will be found that they are no less important, both physiologically and pathologically.

The occurrence of indigo as a deposit in urine is by no means so rare as is ordinarily supposed. Hitherto but two or three well-authenticated cases have been recorded: we have records of several, the particulars of which will form the subject of a separate communication.

Chapter XII. is on "Non-crystalline Organic Deposits," as blood, hæmatosin, albumen, casts of tubuli, purulent and mucous urine, spermatic urine, torulæ, vibriones, sugar, kiestein, fat, urostealith, \&c. This is a highly important chapter, but several of the subjects discussed are treated of much too briefly; it should have been divided into at least three or four other chapters. In some cases, sugar occurs in a semi-crystalline or granular state, and therefore it should certainly have been considered under a different head. The remarks upon the tests for albumen are complete and judicious.

After giving the characters of mucus and pus globules, Dr. Bird proceeds to describe two other forms of globules occasionally found in urine, and which he terms "organic globules," the characters of which are as follow:

The large organic globule, according to Dr. Bird, resembles the mucus particle or globule; being composed of a granular membrane investing a series of transparent nuclei, which become visible on the addition of acetic acid; two nuclei of a crescentic shape, with their concavities opposed, alone being seen in some of the globules.

"I know of no character," states Dr. Bird, "by which these bodies can be distinguished from mucus or pus, excepting that they are unaccompanied with the characteristic albuminous or glairy fluids in which the pus and mucus particles respectively float. The large organic globules seldom form a visible deposit, being free and floating in the urine, and are generally so scattered that not more than a dozen or two are visible at one time in the field of the microscope. They are abundant in the urine of pregnant women, especially in the latter months, when there is a frequent desire to empty the bladder. They have existed in every case of ardor urinæ I have examined, although irritability of bladder was not necessarily present; but when this does exist, they abound. The globule under consideration occurs in the greatest abundance in the albuminous urine of confirmed morbus Brightii : I have seen them so abundant as to cause a drop of the urine to resemble, when microscopically examined, diluted pus - a resemblance rendered more close by the albuminous character of the urine. Is it possible that these globules may here be indicative of sub-acute inflammatory action going on in the structure of the kidney? I am not aware whether they are quite identical with what have been termed the exudation or inflammatory globules of Glüge.

"In a most distressing class of cases, which occasionally occur in practice, where all the symptoms of stone in the bladder exist without any calculus being present, these globules are almost invariably present. This is more especially the case when a roughened state of the interior walls of the bladder can be detected by the sound. A more intractable and distressing ailment hardly exists." *

It will be observed that Dr. Bird gives no characters either as regards size, form, or structure, by which these bodies can be distinguished from either mucus or pus corpuscles; and hence it would appear that there is some danger of confounding them with either those of mucus or pus.

* Loc. cit., pp. 354, 355. 
The small organic globules are described as being very beautiful microscopic objects, much smaller than pus or mucus particles, and essentially distinguished from them by the absolute smoothness of their exterior, no trace of granulation or nucleus being visible even with a high magnifying power. In hot acetic acid they are quite unchanged.

"These globules," according to Dr. Bird, "form a visible white deposit, resembling to the naked eye a sediment of oxalate of lime.

"So rare are these curious little bodies, that comparatively few examples of them have occurred to me; in two, the urine was passed by women during menstruation. It is just possible that they may really be nuclei of some larger nucleated cell, as pus or mucus, and have escaped by the bursting of the investing membrane, or sac of the cell." (p. 356.)

It is desirable that attention should be directed to these two forms of globules, because observers in general do not appear to be acquainted with them.

We have observed another kind of organic globule, differing entirely from either of the above, in several cases of catarrhus vesicæ, and also in simple irritation of the mucous membrane of the bladder, arising from enlarged prostate or other causes, and accompanied by an increased discharge of mucus. Although these globules vary in size, they are usually circular, and many times larger than pus or mucus corpuscles, and contain very distinct granular nuclei, clearly defined, without the aid of acetic acid or any reagent. The number of these nuclei is often very considerable, and they are themselves almost as large as ordinary mucus or pus corpuscles. (See fig. 5.)

These globules closely resemble the parent cells, which are considered to be characteristic of certain forms of malignant disease. There is no reason, however, for supposing that their presence in urine is indicative of any organic affection of the urino-genital organs; and it is highly important, in a practical point of view, that this fact should be borne in remembrance. An observer, not acquainted with these globules, might on first noticing them be led to form the erroneous conclusion, that some malignant or cancerous disease of those organs existed.

The remarks on epithelium are very meagre and unsatisfactory; no attempt is made to discriminate between the different forms of epithelium which occur in urine-as, for example, the epithelium of the tubules of the kidney, of the bladder, of the urethra-and that of the vagina; and yet the epithelia of these several parts differ greatly in their characters. These various forms oceur in urine under very different circumstances, and their presence, therefore, very frequently affords practical information of high value. As one instance, but by no means the most important, showing the utility and even necessity of distinguishing between the different kinds of epithelium met with in urine, it may be mentioned that the urine of woman may, in nearly all cases, be known from that of man by the character of the vaginal epithelium, which is almost constantly present in it in considerable quantity.

The account of the development of the saccharine torula in urine is also very imperfect; and no description is given of penicilium glaucum. Dr. Bird does not refer to the investigations of the reviewer on the development of these fungi in the urine, which were brought before 
Fig. 5.

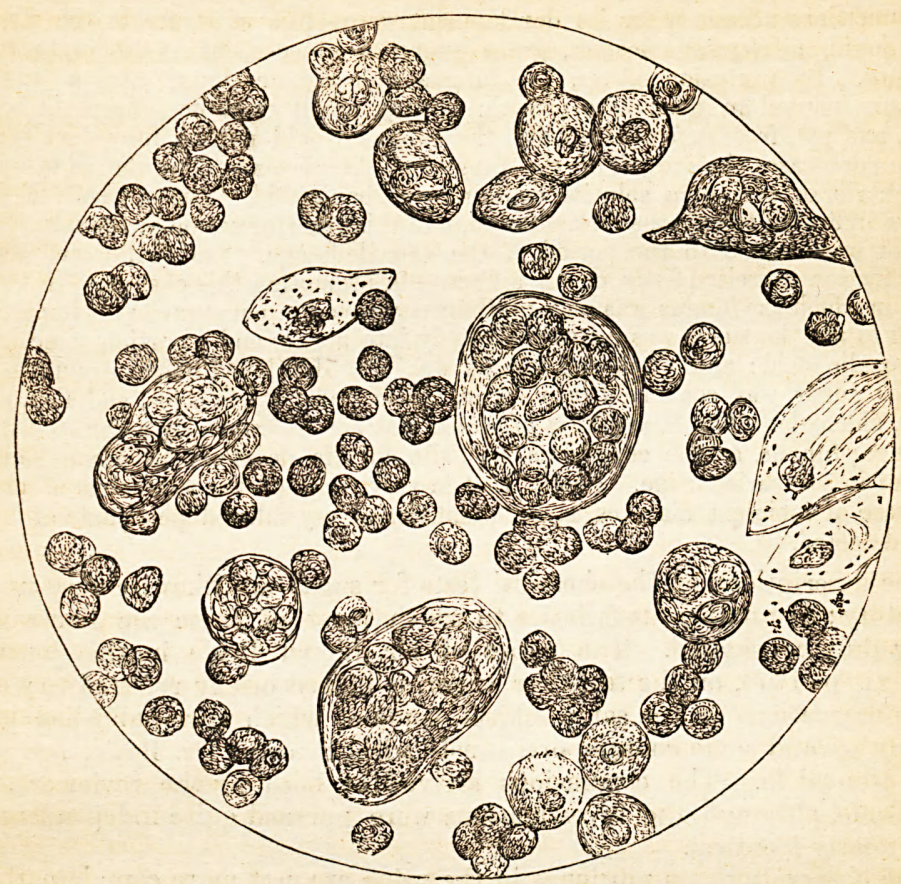

Large compound globules, figured from a case of catarrhus vesicæ with enlarged prostate. Drawn with the camera lucida, and magnified 420 diameters.

the Royal Medico-Chirurgical Society, in November, 1852, and of which abstracts appeared in the different medical journals at the time. The principal conclusions arrived at as the results of these investigations were:-with respect to the development of Penicilium glaucum,

"That this fungus was frequently developed in urine. That the conditions necessary for its growth were, animal matter, especially, but not exclusively; albumen, an acid solution, and oxygen. That it may be developed at will in a variety of animal substances - as in solution of white of egg, acidified with acetic acid. That although the plant does not make its appearance in neutral or alkaline urine, no matter how much albumen may be present, yet that it will quickly become developed in these by acidifying such urines with acetic, phosphoric, or other acids; that its presence may, to a certain degree, be accepted as an indication of the acidity of the urine; that this fungus is no indication whatever of the presence of sugar, nor even of albumen, as a normal quantity of epithelium appears sufficient to induce its growth."

The conclusions with regard to the diabetic torula were-

"That in saccharine urine a distinct species of fungus was developed, which was identical with the yeast plant. That it passed through three distinct stages of growth, each of which is characteristic of the species. That as it was developed in 
urine in which the presence of sugar could not be detected by chemical reagents, it thus became an important means of diagnosing diabetes in its earliest stage. The conditions necessary for its development were-free exposure to the air, an acid liquid, nitrogenous matter, grape sugar or glucose, and a moderate temperature. By exclusion of air, the fungus was not developed, and a limited exposure insured an incomplete growth. Sugar might even be present in some cases, and yet, from defective acidity, the fungus would not be fully developed: and in such cases the growth of the fungus might be insured by the addition of phosphoric, or even of a solution containing carbonic acid. The presence of this fungus indicated the vinous fermentation, and this transformation of the sugar into alcohol was limited to the period of the sporule stage. The thallus and aërial fructification exercised little or no influence in promoting this change. In those cases in which the fungus was only partially developed in consequence of imperfect access of air, the sugar was converted chiefly into acetic, and a portion sometimes into oxalic acid: and when the fungus was not developed from exclusion of air, the sugar was converted into lactic, acetic, and butyric acids, and also, probably, aldehyde. The Penicilium glaucum was not unfrequently associated with the sugar fungus, as the conditions requisite for its development are generally present in saccharine urine. Lastly, that in very many of the specimens of urine in a case of incipient diabetes, large quantities of crystallized phosphate of lime were detected." *

The descriptions of the chemical tests for sugar are likewise very unsatisfactory; the numerous fallacies to which most of these are liable not being duly considered. The paper of Dr. Lionel Beale in this journal (vol. xi. p. 107), on the tests for sugar, is indeed briefly referred to; our own observations on the same subject, some of which were published previously to, and some contemporaneously with, those of Dr. Beale, are not even alluded to. The conclusions arrived at, both by the reviewer and Dr. Beale, although the investigations were pursued quite independently, were nearly identical.

The observations on vibriones in the urine are not more complete than those on the development of torulæ.

Our review of the work of Dr. Bird having already extended to a considerable length, we have no space left for any detailed remarks on the two concluding chapters. One of these, Chapter XIV., is on "Blood Depuration by the Kidneys as a Remedy in Disease." This chapter is entirely new. It contains, amongst other matter, original and important views in reference to the therapeutical action of the acetates, citrates, and tartrates of the alkalies.

We have dwelt thus long upon the work of Dr. Bird, because of the great and daily-increasing importance of the subject of the chemistry and pathology of the urine in the treatment of disease. In the course of our remarks, we have exercised the liberty which we reserved to ourselves at the outset of this review, to comment freely, and we trust impartially, upon such portions of the work as appeared to us to call for special observation. In particular, we have directed attention to those subjects which have been imperfectly, or rather, incompletely treated, partly in consequence of not being brought down to the present state of our knowledge. We have done so in the hope that these omissions will be supplied in any future editions of the work, and that such will be made to reflect fairly the state of the several subjects up to the periods of their publication. 
The advances made in any department of the science of medicine are surely slow enough; any work, therefore, professing to treat systematically of any branch of such science, should certainly give the most complete, as well as the latest, information on all subjects falling within its range; not to do so, is to render that progress, already slow, still slower; for information is thus withheld from the reader, of which he would no doubt, in many cases, make profitable use.

Regarding, then, the work of Dr. Golding Bird as a whole, we would say of it, on the one side, that it is less perfect and complete than could be desired, or than, with a little additional labour, it might very easily have been rendered; and, on the other, that it is clearly written; that the arrangement of the materials is good; that it contains many original views; and that it is eminently practical, and hence, well adapted as a guide to the student or practitioner. So excellent is the work in this respect, that its equal is not to be found up to the present time, either in this or in any other language.

Arthur Hill Hassall.

\section{Review XI.}

Die Rationalität der Molkencuren, eine Empfehlungsschrift für die Molkenanstalt zu Bad Rehburg. Von Dr. F. W. Beneke.-Hannover, Helwing, 1853. pp. 72.

The Rationale of Whey-cures. By Dr. Beneke.

Those who are conversant with German medical literature are aware that whey has long been employed as a curative agent in various ailments of a chronic character. Romberg, to mention a name now familiar to English readers, frequently recommends its employment as a mild restorative in nervous affections; and different methods in which it may be prepared have been admitted among the officinal directions of several of the German Pharmacopœias.* It is probable that the subject may soon attract the notice of the non-medical public of Great Britain, and the necessary consequence will be, the establishment of a "Whey-cure" institution in some lovely spot of Devonshire or Kent, on purely commercial grounds, with all those adjuncts of puffing and advertising which forebode an early death to the undertaking. We wish to save the whey-cure from the obloquy of becoming a mere

* The following is a translation of the directions given in the 'Pharmacopœia Borussica' of 1829, for the preparation of five different kinds of whey:

1. Serum lactis dulce, sweet whey.-Take an ounce of the dried stomach of a calf, infuse with six fluid ounces of cold water for ten or twelve hours, add an ounce of this liquor to nine pounds of fresh cow's milk, warm gently, and after coagulation is effected, decant and strain the liquid.

2. Serum lactis dulcificatum, sweetened whey.-Take three pounds of cow's milk, boil, and at the commencement of ebullition add one drachm of bitartrate of potash; when the coagulation is effected, and the whole has become cool, strain, and boil with a sufficient quantity of white of egg beaten up into a froth, until the albumen is coagulated; strain, and add as much prepared chalk (or shells) as is required to neutralize the acid, and filter.

3. Serum lactis acidum, sour whey.-The former without addition of the chalk.

4. Serum lactis aluminatum, alum whey. 5. Serum lactis tamarindinatum, tamarind whey.-In these respectively a drachm of crude powdered alum, or one ounce of the pulp of tamarinds, are employed instead of the bitartrate of potash.

Other pharmacopœias direct the preparation of a variety of whey with vinegar, or with Rhenish wine; in the latter case the proportions are eight ounces of wine to three pounds of milk. 